\title{
New interventional cardiology devices, CRT survey in Turkey, and more
}

Mitral paravalvular leaks (PVLs) are not uncommon in patients with prosthetic valves. Gürsoy et al., from Turkey, summarize the etiopathogenesis, clinical characteristics, diagnosis, and treatment of mitral PVLs in a review that includes their experience.

Arslan et al., from Turkey, report on their first experiences with the Myval valve (Meril Life Sciences, Pvt. Ltd., Vapi, Gujarat, India) in a scientific letter. This recently developed, balloon-expandable prosthetic valve demonstrated clinical efficacy and safety in the Myval-1 study.

Supraflex (Sahajanand Medical Technologies Pvt. Ltd., Surat, Gujarat, India) is a latest generation, biodegradable, polymer-coated, sirolimus-eluting coronary stent designed to use an ultra-thin $(60 \mu \mathrm{m})$ cobalt-chromium platform and a flexible S-link. The study performed by Nathani et al. from India established excellent safety and clinical performance in Indian patients with coronary artery disease. This is a valuable new contribution to interventional cardiology.

Radiofrequency ablation is a safe and effective method used in the definitive treatment of pediatric tachyarrhythmia. Kafalı et al., from Turkey, share their experience with ablative modalities (radiofrequency ablation and cryoablation) in children with tachycardia-induced cardiomyopathy. This research adds interesting new data about the results of ablation therapy in this group.

Yiğit et al., from Turkey, discuss adding T1 mapping to the routine cardiac MRI protocol to evaluate diffuse myocardial fibrosis in surgically corrected Tetralogy of Fallot patients.

The first observational data reflecting the current cardiac resynchronization therapy practice in Turkey (CRT Survey) were collected by Koçyiğit et al., from Turkey, and compared with those of Europe. These findings may help detect gaps and provide insights for improvement.

Aslan et al., from Turkey, evaluated the levels of serum platelet-derived growth factor-beta and brainderived neurotrophic factor in patients with microvascular angina (MVA) and assess possible associations with other atherosclerotic risk factors. This work helps to shed light on the mysteries of the pathogenesis of MVA.

Possible gender differences in the distribution of focal atrial tachycardia in a large cohort of patients referred for ablation were the subject of a study reported by Türkmen et al., from Sweden. This should be taken into consideration in the management of this type of tachycardia.

As always, we are also pleased to offer numerous interesting case reports, e-page originals, and letters.

I hope this issue will be of interest to our readers.

Prof. Dr. Çetin Erol

Editor-in-Chief

Ankara-Turkey

Address for Correspondence: Prof. Dr. Çetin Erol, Ankara Üniversitesi Tıp Fakültesi, İbn-i Sina Hastanesi, Kardiyoloji Anabilim Dalı, Ankara, Türkiye

Phone: +90 3123103333 /27 79 E-mail: ctnerol@yahoo.com

(C) Copyright 2020 by Turkish Society of Cardiology - Available online at www.anatoljcardiol.com DOl:10.14744/AnatolJCardiol.2020.12 